\title{
O DEBATE SOBRE O DÉFICIT PREVIDENCIÁRIO E UMA ANÁLISE DAS (IN)CONSTITUCIONALIDADES DA PEC 06/2019
}

\author{
${ }^{1}$ Joaner Campello de Oliveira Junior \\ ${ }^{2}$ Carlos Alberto Simões de Tomaz
}

\section{Resumo:}

O tema sobre a reforma da previdência desde a Constituição de 1988 sempre esteve presente no debate político nacional. Mais recentemente após o impeachment de Dilma Rousseff retoma-se a discussão sobre previdência no país seja pela EC 287/2016 e de forma mais atual por meio da EC 06/2019. Embora o debate político esteja centrado na questão do déficit da seguridade social, faz-se necessário analisar em que medida a capitalização, o BPC e a desconstitucionalização da matéria previdenciária confrontam a constituição brasileira e as normas internacionais. Para isso, será utilizado o método histórico e dedutivo e a pesquisa bibliográfica.

Palavras-Chave: Constituição. Direitos Humanos. Previdência. Solidariedade

\section{THE DEBATE ON THE SOCIAL SECURITY DEFICIT AND AN ANALYSIS OF THE (UN) CONSTITUTIONALITIES OF PEC 06/2019}

\begin{abstract}
:
The theme of social security reform since the 1988 Constitution has always been present in the national political debate. More recently, after Dilma Rousseff's impeachment, the discussion on social security in the country appears in the EC 287/2016 and more recently through the EC 06/2019. Although the political debate is centered on the social security deficit issue, it is necessary to analyze if themes like capitalization, the BPC and the deconstitunalization of social security confront the Brazilian constitution and international law. For this, the historical and deductive method and the bibliographic research will be used.
\end{abstract}

Keywords: Constitution. Human Rights. Social Security. Solidarity.

\section{INTRODUÇÃO}

A promulgação da Constituição Federal de 1988 inovou ao estabelecer a seguridade social como conceito organizador da proteção social no país. Ampliou a cobertura do sistema previdenciário e flexibilizou o seu acesso para os trabalhadores rurais, reconheceu a

\footnotetext{
${ }^{1}$ Advogado. Pós-Graduado em Direito Público e Tributário pela AVM Educacional. Mestre em Direito das Relações Internacionais e da Integração Latino Americana pela Universidad de la Empresa - Uruguai. E-mail: joanercampello@hotmail.com.

${ }^{2}$ Mestre em Direitos das Relações Internacionais (UNICEUB/DF). Doutor em Direito Público (UNISINOS/RS). Pós-Doutor em Filosofia do Direito (Universidade de Coimbra).
} 
importância da assistência social como politica pública, oferecendo serviços e benefícios monetários, além de vislumbrar a universalização do atendimento à saúde por meio do Sistema Único de Saúde (SUS).

Sem embargo, após 1988 o texto constitucional sofreu ao longo dos anos múltiplas emendas, mitigando os benefícios previdenciários pactuados na nossa Carta Política conforme será observado neste trabalho. Inclusive, tramita no Congresso Nacional a EC n06/2019 com o fito de promover modificações no sistema previdenciário. Não se pode olvidar que a discussão sobre as alterações no sistema previdenciário gira em torno da crise fiscal que passa o Estado brasileiro e pelas diferentes visões sobre a existência dos déficits previdenciários, aliado a questão do envelhecimento da população brasileira.

Neste contexto, é atual e relevante analisar a luz dos comandos constitucionais vigentes alguns dos preceitos insculpidos na emenda constitucional $n^{\circ}$ 06/2019 como a revisão do BPC (benefício de prestação continuada), a desconstitucionalização da matéria previdenciária e a insistência governamental em instituir o regime previdenciário de capitalização.

Para isso, será apresentada resumidamente a questão assistencial e previdenciária no Brasil até a promulgação da CFRB/88, introduzindo o tema da seguridade social na $\mathrm{CF} / 88$, assim como as reformas realizadas. Diante das diferentes visões quanto ao déficit da previdência faz-se necessário pontuar sobre os diversos pontos de vista e, por fim, verificar as (in) constitucionalidades contidas no texto que visa à reforma do sistema de proteção social brasileiro. Será utilizado o método dedutivo e o método histórico para delinear os desdobramentos do tema previdenciário no Brasil e a pesquisa bibliográfica cujas fontes foram extraídas da literatura especializada impressa e digital.

\section{BREVE RESUMO HISTÓRICO DA PREVIDÊNCIA NO BRASIL ATÉ A CONSTITUIÇÃO DE 1988}

O surgimento de um sistema de previdência no Brasil atravessa os séculos. A primeira concepção de um sistema de previdência surgiu em 1543 na ocasião da fundação da Santa Casa de Misericórdia de Santos, por Brás Cubas, que realizava prestações assistenciais.

Após mais de dois séculos de fundação da Santa Casa foi aprovado por D. João VI o Plano dos Oficiais da Marinha, em 1793. Em 1935, foi criado o MONGERAL, por meio da 
aprovação do Montepio Geral da Economia dos Servidores do Estado (MONGERAL) que representa o marco da previdência complementar no Brasil.

A partir de 1888 surgiram diversas leis com o escopo de regular a aposentadoria e pensões para vários segmentos profissionais no país. Por exemplo, o Decreto n 9912-A/1888 (aposentadoria dos empregados dos Correios); Decreto $n^{\circ}$ 10.269/1889 (Fundo de pensões do pessoal das oficinas de imprensa); o Decreto $\mathrm{n}^{\circ}$ 221/1890 (instituiu o sistema de aposentadoria dos empregados da Estrada de Ferro Central do Brasil) e a Lei n ${ }^{\circ}$ 3.724/1919 (tornou compulsório o seguro contra acidentes de trabalho para determinadas atividades).

Não obstante, o ponto de partida regulatório para a Previdência Social no Brasil se deu com o Decreto $n^{\circ}$ 4.682/1923, conhecido como Lei Elói Chaves, estabelecendo a criação de Caixas de Aposentadorias e Pensões para os empregados ferroviários. Posteriormente, a Lei ${ }^{\circ}$ 5.109/1926 estendeu o regime da Lei Elói Chaves para os portuários e marítimos; a Lei 5.485/1928 concedeu o mesmo regime aos trabalhadores dos serviços telegráficos e radiotelegráficos e, em 1932, os trabalhadores das empresas de mineração também foram inseridos neste mesmo regime.

Em 1934, o art. 121 da Constituição fez a primeira menção sobre a instituição da previdência, mediante contribuição igual da União, do empregador e do empregado, a favor da velhice, da invalidez, da maternidade e nos casos de acidentes de trabalho ou de morte.

Depois de 1934 começaram a surgir por meio diversas iniciativas legislativas os institutos de aposentadorias e pensões de várias categorias profissionais. O Decreto 24.272/1934 criou o Instituto de Aposentadoria e Pensões dos comerciários (IAPC); o Decreto $\mathrm{n}^{\circ}$ 54.615/1934 estabeleceu a criação de órgão semelhante para os bancários (IAPB); a Lei 367/1936 instituiu o Instituto de aposentadoria dos Industriários (IAPI), dentre outros.

Finalmente, em 26 de agosto de 1960, foi criada a Lei Orgânica da Previdência Social pela Lei ${ }^{\circ} 3.807$, unificando a legislação referente aos Institutos de Aposentadorias e Pensões, ao passo que o Decreto $\mathrm{n}^{\circ}$ 48.959-A aprovou o regulamento geral da previdência social. Mais tarde, o Decreto-lei $n^{\circ}$ 66/1966 alterou dispositivos na Lei Orgânica da Previdência Social relativos às prestações e ao custeio, enquanto o Decreto-Lei n 72/1966 reuniu os seis Institutos de Aposentadorias e Pensões existentes, criando o Instituto Nacional de Previdência Social - INPS.

No intuito de aprimorar a legislação e o manuseio das regras foi criado pela Lei $\mathrm{n}^{\circ}$ 6.439/1977 o SINPAS (Sistema Nacional e Previdência e Assistência Social), sendo 
englobado por sete (07) órgãos: IAPAS (administração financeira), INPS (concessão e manutenção dos benefícios previdenciários), INAMPS (assistência médica), DATAPREV (processamento de dados), LBA (legião brasileira de assistência), CEME (central de medicamentos), FUNABEM (assistência e bem estar do menor).

Com a promulgação da Constituição de 1988 foi instituída a Seguridade Social, prevendo o custeio tripartite entre União, Estados, Municípios e Distrito Federal, trabalhadores e empregadores, incorporando três áreas de atuação: assistência social, saúde e previdência social.

Em 1990, sobreveio a criação do Instituto Nacional do Seguro Social mediante a fusão do IAPAS com o INPS pelo Decreto $n^{\circ}$ 99.350/1990. A Lei $n^{\circ}$ 8.212/1991 passou a regular a organização da Seguridade Social e o seu plano de custeio e a Lei 8.213/91 instituiu o Plano de Benefícios da Previdência Social.

Todavia, a partir de 1988 diversas emendas constitucionais foram realizadas sob o argumento de racionalizar as normas relativas à seguridade social, em especial, a questão da previdenciária e o seu equacionamento fiscal, frutos de intensos debates em todos os governos desde a redemocratização. Com este escopo foram aprovadas as $\mathrm{EC} \mathrm{n}^{\circ} 03,20,41,47,70$ e 88 que produziram mudanças significativas no trato dos direitos sociais e na proteção social que por opção didática estão descritas em tópico próprio.

\section{A SEGURIDADE SOCIAL NA CONSTITUIÇÃO DE 1988}

A expressão seguridade social teve seu primeiro uso formal na ocasião da criação da Previdência Social dos Estados Unidos, em 1935, por meio do lançamento do social security act e na elaboração de políticas sociais que buscavam resgatar as pessoas da condição de pobreza na Inglaterra, em 1942. (AMORIM, 2017).

Com fim da Segunda Guerra e as atrocidades decorrentes do conflito armado se exsurgiu uma nova visão de proteção social em conjunto com a criação do Estado de Bem Estar Social (Welfare State). Neste contexto, nasceu a Declaração Universal dos Direitos Humanos da Organização das Nações Unidas (ONU), expressando no art. XXII que todo ser humano, como membro da sociedade, tem o direito à segurança social. (ONU, 1948). Mais tarde, foi aprovada a Convenção $\mathrm{n}^{\circ} 102$ da OIT que trata sobre normas mínimas de seguridade social, internalizada na ordem jurídica pátria mediante o Decreto Legislativo n 269/2008. 
Constitucionalmente, o art. 194 da CFRB/88 determina que a seguridade social compreende um conjunto de ações integradas, de iniciativa dos Poderes Públicos e da sociedade, destinadas a assegurar os direitos relativos à previdência, à saúde e à assistência social.

Para Delgado, Jaccoud e Nogueira (2009, p.21) o termo seguridade social é "um conceito estruturante das politicas sociais cuja principal característica é de expressar o esforço de garantia universal da prestação de benefícios e serviços de proteção social pelo Estado". A seguridade social pode ser compreendida segundo Ibrahim (2012) como um sistema de proteção formado pelo Estado e por particulares, com contribuições de todos, inclusive de parte de seus beneficiários, destinado a promover ações que garantam uma vida minimamente digna para pessoas carentes, trabalhadores em geral e seus dependentes.

Embora a seguridade social tenha o objeto de articular as politicas de seguro e assistência social, saúde e seguro-desemprego, fundando-se em um conjunto de políticas com vocação universal, faz-se necessário ressaltar que o modelo consagrado na CRFB/1988 não contou com o respaldo de movimentos e lideranças da sociedade civil durante o processo constituinte. (DELGADO; JACCOUD; NOGUEIRA, 2009).

Mesmo diante de impasses a $\mathrm{CF} / 88$ acabou combinando o paradigma universalista (saúde e previdência social), contributivo (previdência urbana) e seletivo (assistência social); dentro dos limites de cada um destes tipos clássicos de proteção social do pós-guerra. (DELGADO; JACCOUD; NOGUEIRA, 2009).

Assim, a CRFB/88 para consagrar a seguridade social traz no seu texto uma constelação de princípios, dentre eles: solidariedade, universalidade da cobertura e do atendimento, uma uniformidade e equivalência dos benefícios e serviços entre as populações urbanas e rurais, seletividade e distributividade dos benefícios e serviços, irredutibilidade do valor dos benefícios, equidade na forma de participação do custeio, diversidade na base do financiamento, caráter democrático e descentralização da administração.

Embora não represente um principio explícito da seguridade social, a solidariedade é um dos objetivos fundamentais da República Federativa do Brasil inserto no inciso I do art. $3^{\circ}$ da $\mathrm{CF} / 88$. Este princípio pode ser analisado por duas diferentes óticas. A horizontal que representa a distribuição de renda entre as populações (pacto intra-geracional) e a vertical em que uma geração deve trabalhar para pagar os benefícios das gerações passadas (pacto intergeracional). (KERTZMAN, 2013). 
O inciso I do art. 194 explicita o principio da unidade da cobertura e do atendimento. A universalidade do atendimento preconiza que todos devem estar cobertos pela proteção social. Além disso, representa uma universalidade subjetiva, pois se refere ao sujeito da relação jurídica previdenciária, seja o segurado ou o seu dependente. Assim, para atender a universalidade do atendimento a legislação previdenciária faculta a filiação aqueles que não exercem atividade remunerada abrangida pelo sistema previdenciário, denominado segurado facultativo. De outro turno, a universalidade da cobertura, de natureza objetiva, determina que a proteção da seguridade deve abranger todos os riscos sociais. (KERTZMAN, 2013).

No inciso II do art. 194 da CF/88 encontra-se o princípio da uniformidade e equivalência dos benefícios e serviços às populações urbanas e rurais. Este princípio inserido no texto constitucional tem o condão de corrigir as distorções criadas pela legislação previdenciária rural para os seus beneficiários. (MARTINS, 2004).

A seletividade e distributividade na prestação dos benefícios e serviços inserta no inciso III do art. 194 implica que as prestações sejam fornecidas apenas aqueles que necessitem, desde que enquadrados nas situações definidas por lei. Por exemplo, a prestação do auxílio doença para aqueles segurados incapacitados temporariamente para o trabalho. Por outro aspecto, a seletividade representa um contrapeso ao princípio da universalidade de cobertura, vez que, embora seja necessário cobrir todos os riscos sociais existentes, sabe-se que os recursos não são ilimitados, cabendo à administração a seleção dos benefícios e serviços prestados com base na relevância dos riscos sociais. (KERTZMAN, 2013).

O princípio constitucional da irredutibilidade do valor dos benefícios expresso no inciso IV do art. 194 comporta duas interpretações distintas. A primeira afirma que deve ser mantido o poder aquisitivo real dos benefícios, enquanto a segunda corrente determina que o valor nominal dos benefícios não pode ser reduzido. Vale ressaltar que o próprio $\S 4^{\circ}$ do art. 201 do texto constitucional assegura expressamente o reajustamento dos benefícios para preservar-lhes, em caráter permanente, o valor real, conforme critérios definidos em lei. A MP $316 / 2006$, convertida na Lei $n^{\circ} 11.430 / 2006$ e alterada pela Lei $n^{\circ} 12.254 / 2010$ fez inserir o art. 41-A na Lei 8.213/91, afirmando que o valor dos benefícios em manutenção será reajustado, anualmente, na mesma data do reajuste do salário mínimo, pro rata, de acordo com suas respectivas datas de início ou do último reajustamento, com base no Índice Nacional de Preços ao Consumidor - INPC, apurado pelo Instituto Brasileiro de Geografia e Estatística IBGE. 
Enquanto isso, o art. 58 do ADCT determina que: os benefícios de prestação continuada, mantidos pela previdência social na data da promulgação da Constituição, terão seus valores revistos, a fim de que seja restabelecido o poder aquisitivo, expresso em número de salários mínimos, que tinham na data de sua concessão. Por oportuno, o STF editou a Súmula 687, estabelecendo que a revisão mencionada no art. 58 do ADCT não se aplica aos benefícios previdenciários concedidos após a promulgação da Constituição de 1988. Derradeiramente, não se pode olvidar que a própria constituição no inciso IV do art. $7^{\circ}$ veda expressamente qualquer espécie de vinculação ao salário mínimo.

A equidade na forma de participação do custeio expressa no inciso V do art. 194 da CFRB/88 delimita que a participação do custeio da seguridade social deve considerar a capacidade de cada contribuinte, ou seja, cobrar maiores contribuições de quem tem maiores condições contributivas para que possa beneficiar aqueles que não possuem as mesmas condições. (KERZMAN, 2013). Assim, representa a busca pelo equilíbrio entre a capacidade econômica dos contribuintes e o esforço financeiro que eles necessitam para a manutenção da seguridade social, impulsionando a redução das desigualdades sociais.

Segundo Ibrahim (2012) o princípio da base de diversidade de financiamento teve origem na tríplice fonte de custeio estabelecida na Constituição de 1934 e atualmente, de forma mais abrangente, mantém a sua essência ao prever que o custeio da seguridade deve envolver a contribuição de trabalhadores, as empresas e o governo, evitando que as oscilações econômicas não venham a prejudicar a cobertura ou o atendimento da seguridade em virtude do seu variado leque de contribuições. A preocupação com a diversificada base de financiamento da seguridade social se cristaliza no rol estabelecido no art. $195^{3}$ da CF/88.

O caráter democrático e descentralizado da administração, mediante gestão quadripartite, com participação dos trabalhadores, dos empregadores, dos aposentados e do

\footnotetext{
${ }^{3}$ Art. 195. A seguridade social será financiada por toda a sociedade, de forma direta e indireta, nos termos da lei, mediante recursos provenientes dos orçamentos da União, dos Estados, do Distrito Federal e dos Municípios, e das seguintes contribuições sociais: I - do empregador, da empresa e da entidade a ela equiparada na forma da lei, incidentes sobre: a) a folha de salários e demais rendimentos do trabalho pagos ou creditados, a qualquer título, à pessoa física que lhe preste serviço, mesmo sem vínculo empregatício; b) a receita ou o faturamento; c) o lucro; II - do trabalhador e dos demais segurados da previdência social, não incidindo contribuição sobre aposentadoria e pensão concedidas pelo regime geral de previdência social de que trata o art. 201; III - sobre a receita de concursos de prognósticos; IV - do importador de bens ou serviços do exterior, ou de quem a lei a ele equiparar.
} 
Governo nos órgãos colegiados foi introduzido com a nova redação dada ao inciso VII do art. 195 da CF/88 pela Emenda Constitucional $n^{\circ}$ 20/1998. Antes da emenda o texto constitucional prescrevia que a participação da comunidade, em especial, trabalhadores, empresários e aposentados, sem instituir a gestão nos atuais moldes.

Com o fito de atender a gestão quadripartite foram criados diversos colegiados como o Conselho Nacional de Previdência Social - CNPS; Conselho Nacional de Assistência Social - CNAS; Conselho de Previdência Social - CPS; Conselho Nacional de Previdência Complementar - CNPC, entre outros. Assim, a gestão quadripartite deve contar com a participação de representantes de todos os grupos que se relacionam com a seguridade social.

Por derradeiro, o texto constitucional prescreve que devem ser elaborados anualmente e aprovados por lei três orçamentos: o orçamento fiscal, o orçamento de investimento, e orçamento da seguridade social. Este último que é específico deve conter as receitas da seguridade social e os gastos com as áreas de saúde, assistência social e previdência social. De outro bordo, as receitas dos Estados, do Distrito Federal e dos Municípios destinadas à seguridade social constarão dos respectivos orçamentos, não integrando o orçamento da União.

Em sede infraconstitucional, o parágrafo único do art. 16 da Lei 8.212/91, determina que a União é responsável pela cobertura de eventuais insuficiências financeiras da Seguridade Social, quando decorrentes do pagamento de benefícios de prestação continuada da Previdência Social, na forma da Lei Orçamentária Anual.

Portanto, percebe-se que o legislador constituinte na conformação da Seguridade Social optou por um amplo leque de cobertura, pautado na ideia de construir uma sociedade livre, justa e solidária que se propõe a erradicar a pobreza e a marginalização, assim como a redução das desigualdades.

\subsection{AS REFORMAS DA PREVIDÊNCIA APÓS A CONSTITUIÇÃO DE 1988}

Embora o texto constitucional promulgado em 1988 tenha construído um amplo sistema de proteção social não quer dizer que o debate na sua construção tenha sido coeso e pacificado entre os diversos setores constituintes. Neste aspecto, consoante Fagnani (2017) desde os trabalhos da Assembleia Nacional Constituinte (ANC), as elites se esforçam para comprovar a inviabilidade financeira da previdência, propondo formas de retroceder as conquistas do texto constitucional. Neste diapasão, o autor descreve a convocação realizada 
por José Sarney em cadeia nacional de rádio e televisão para alertar o povo e os constituintes que alguns aspectos no texto aprovado, no primeiro turno de votação, representavam um risco para o país, tornando-o ingovernável, vez que, a Seguridade Social explodiria os gastos públicos. Inclusive, esta tese da ingovernabilidade foi realimentada em diversos momentos nas décadas seguintes por diversos autores como Roberto Campos (1994), Maílson da Nóbrega (2005), Samuel Pessoa (2007) e Fabio Giambiagi (2007).

Não se pode olvidar que os constituintes de 1988 previram uma revisão da Constituição a ser realizada em 1993, integralmente, pela maioria absoluta dos votos do Congresso Nacional. No entanto, a instabilidade política pelo impeachment de Collor enterrou a estratégia de formulação de uma ampla agenda de reformas e com isso inviabilizou a revisão constitucional. (FAGNANI, 2017). Este cenário, não concretizou o temor de parlamentares oposicionistas quanto a possibilidade da reorganização do grupo político conhecido como "centrão" que poderia impor retrocessos aos avanços sociais consagrados na Constituição, afinal nos primeiros anos de vigência o texto constitucional fora duramente criticado por empresários, sob o argumento de que ela apresentava direitos em excesso e poucos deveres para os trabalhadores e cidadãos. (SENADO FEDERAL, 2008).

Este revisionismo constitucional está presente desde 1988 tanto que a previdência já passou pelas emendas constitucionais $n^{\circ}$ 03/1993, 20/1998, 41/2003, 47/2005, 70/2012, 88/2015. Também não se pode esquecer a extinção do Conselho Nacional de Seguridade Social, órgão superior de deliberação colegiada, com a participação da União, dos Estados, do Distrito Federal, dos Municípios e de representantes da sociedade civil inserto na Lei 8.212/1991, mas revogado pela MP 2.216-37/2001 num claro retrocesso de participativo.

Cronologicamente, a primeira modificação em matéria previdenciária ocorreu por meio da EC 03/93 durante o governo Itamar Franco, determinando que as aposentadorias e pensões dos servidores fossem custeadas com recursos provenientes da União e das contribuições dos servidores (EC 03/93, art. 40, §6 $6^{\circ}$ ).

A EC 20/98 promulgada durante o governo FHC realizou uma reforma mais ampla, abrangendo todos os sistemas de previdência tanto no setor público, como no privado. Para o setor privado as modificações foram à substituição do tempo de serviço para tempo de contribuição ao INSS $\left(\S 1^{\circ}\right.$ do art. $\left.9^{\circ}\right)$, fixação das idades mínimas para aposentar, sendo 48 anos para as mulheres e 53 anos para os homens com tempo de contribuição de 30 anos para as mulheres e 35 anos para os homens. (art. $9^{\circ}$ ). Todavia, a EC 20/98 assegurou o 
direito adquirido para os trabalhadores públicos ou privados que, até 16 de dezembro de 1998, tivessem cumprido os requisitos propostos na legislação anterior.

Ainda durante o governo FHC foi promulgada a MP 2.215-10/2001 que dispôs sobre a reestruturação da remuneração dos militares das forças armadas, alterando as Leis $\mathrm{n}^{\circ} 3.765 / 1960$ e 6.880/1980. A medida provisória no seu texto acrescentou a alíquota da contribuição para pensão militar de 7,5\% (sete vírgula cinco por cento), o fim das pensões vitalícias e o direito a percepção do soldo integral ao passar para a reserva remunerada ex officio.

Em 2003, durante o primeiro governo Lula, a EC 41/03 trouxe modificações em matéria previdenciária centradas nos servidores públicos. Inseriu a média de todas as remunerações para efeito de cálculo das aposentadorias dos servidores; cobrança de contribuição previdenciária para os servidores já aposentados e aplicação de teto salarial nas esferas federal, estadual e municipal.

A EC 47/2005 inovou com a previsão de um sistema de cobertura previdenciária com contribuições e carências reduzidas para beneficiar trabalhadores de baixa renda e aqueles sem renda própria que se dediquem exclusivamente a trabalho doméstico no âmbito de sua residência, desde que pertencente a famílias de baixa renda, estando garantido o benefício a um salário mínimo. Por outro lado, dispunha que as contribuições sociais poderiam ter alíquotas ou bases de cálculo diferenciadas, em razão da atividade econômica, da utilização intensiva de mão-de-obra, do porte da empresa ou da condição estrutural do mercado de trabalho.

Durante os governos de Dilma Rousseff sobrevieram as duas últimas alterações previdenciárias. A EC 70/2012 voltada para estabelecer os critérios para o cálculo e a correção dos proventos de aposentadoria por invalidez e a EC 88/2015 estabeleceu a idade para a aposentadoria compulsória aos 75 anos de idade do servidor público.

Neste ano, o governo brasileiro editou a MP $n^{\circ} 871 / 2019$ convertida na Lei $n^{\circ}$ 13.846/2019 com o intuito de combater fraudes no INSS. Todavia, segundo a Nota Técnica $\mathrm{n}^{\circ}$ 01 do $\operatorname{IBDP}^{4}$ a referida Lei contém pontos juridicamente espinhosos. A previsão do programa especial de análise de benefícios com indícios de irregularidades pode vir a presumir má-fé dos aposentados; o pagamento de bônus aos servidores para a referida análise pode representar violação ao princípio da moralidade, caso o pagamento do bônus sirva como

\footnotetext{
${ }^{4}$ Instituto Brasileiro de Direito Previdenciário
} 
benefício financeiro para cassação de aposentadorias; a grande elasticidade do conceito de benefício previdenciário com indício de irregularidade; inconstitucionalidade do devido processo legal no procedimento de revisão previsto na lei; ilegalidade e inconstitucionalidade na exigência de prova da união estável e da dependência econômica. (IBPD, 2019)

Por fim, enquanto no governo Temer a PEC 287/2016 não logrou êxito, agora sob o governo Bolsonaro tramita a PEC 06/2019, expondo riscos ao sistema constitucional de seguridade social no Brasil.

\section{AS DIFERENTES VISÕES SOBRE O SUPOSTO DÉFICIT DA PREVIDÊNCIA}

A discussão sobre o déficit da previdência não é algo novo na nossa jovem redemocratização conforme já mencionado no tópico anterior. Pelo contrário, remonta aos embates pelos setores constituintes que culminaram na aprovação e promulgação do texto constitucional e serviram de combustível para as reformas posteriores a 1988.

Cambraia (2019) no estudo técnico $n^{\circ}$ 10/2019 afirma que existe um crescente resultado negativo no orçamento da seguridade social, particularmente, a partir de 2008 independentemente do efeito da desvinculação das receitas da União, embora deva se salientar que o levantamento carece de maior aprofundamento nos dados apurados.

Embora o governo e alguns setores mantenham a defesa da existência do déficit previdenciário, o tema esta longe de ser consensual. Fattoreli (2017), ao criticar a versão governamental acerca do déficit da previdência, exige que sejam apresentados os dados completos do orçamento da seguridade social, informando os montantes desviados por meio da DRU; os montantes correspondentes às desonerações concedidas tanto ao setor urbano como o rural; os créditos tributários não executados e ainda a elevação do desemprego que mantem grande contingente populacional fora do mercado de trabalho.

No mesmo sentido, Gentil (2006), na tese de doutorado, intitulada a política fiscal e a falsa crise de seguridade social brasileira - Análise financeira do período 1990-2005, afirma que o denominado déficit da previdência é, no entanto, saldo previdenciário negativo resultante da soma parcial de receitas oriundas das contribuições do INSS sobre a folha de salários e demais rendimentos do trabalho e de outras receitas próprias menos expressivas, deduzidas das transferências a terceiros e dos benefícios previdenciários do RGPS, afirmando que o uso da inadequada metodologia para a avaliação do desempenho financeiro da 
previdência se dissocia da sistemática constitucional da criação de um sistema integrado de seguridade social que abrange a saúde, a assistência social e a previdência.

O Senado Federal após a instauração da Comissão Parlamentar de Inquérito (CPI) para investigar a contabilidade da previdência social, esclarecendo com precisão as receitas e despesas do sistema, bem como todos os desvios de recursos (CPIPREV), no seu relatório final apresentou o entendimento pela existência de um superávit no sistema de Seguridade Social, tendo em vista que o resultado das receitas e despesas devem ser analisadas como um todo, e não separadamente, com fundamento nos artigos 165, 194 e 195 da CF.

Fatorelli (2019) com base nos dados segregados anualmente pela ANFIP afirma que desde a aprovação da Constituição até 2015 (inclusive) o superávit de recursos na Seguridade Social tem sido impressionante. A sobra de recursos foi, por exemplo, de $\mathrm{R} \$ 72,7$ bilhões em 2005; R \$ 53,9 bilhões em 2010; R \$ 76,1 bilhões em 2011; R \$ 82,8 bilhões em 2012; R \$ 76,4 bilhões em 2013; R \$ 55,7 bilhões em 2014; e R \$11,7 bilhões em 2015.

Diante deste contexto é preciso relembrar que o legislador constituinte pátrio estabeleceu no inciso VI do art. 194 que compete ao Poder Público organizar a seguridade social com base na diversidade do financiamento. Neste aspecto, o art. 195 diz que a seguridade social será financiada mediante recurso dos orçamentos da União, dos Estados, do Distrito Federal, dos Municípios e das contribuições sociais.

Do ponto de vista infraconstitucional também se observa a exigência constitucional da diversidade de financiamento como a responsabilidade União para custear a seguridade social. Assim, o $\S 1^{\circ}$ do art. 68 da Lei Complementar $n^{\circ}$ 101/2000 de forma clara determina que o sistema de seguridade social é formado pela contribuição dos empregadores, trabalhadores e pelo Estado. Já, o parágrafo único do art. 16 da Lei 8.212/91 impõe que é responsabilidade da União à cobertura de eventuais insuficiências financeiras da Seguridade Social, quando decorrentes do pagamento de benefícios de prestação continuada da Previdência Social, na forma da Lei Orçamentária Anual.

Embora o art. 68 da Lei Complementar $n^{\circ}$ 101/2000 reafirme que a seguridade social deve ser custeada pela contribuição dos empregadores, empregados e pelo Estado, também, traz um desarranjo constitucional. A previsão de criar um Fundo do Regime de Previdência Social exclusivo desconstrói o conceito de seguridade social estabelecido no texto constitucional. Para Gentil (2006) esta proposta acarretou a consideração equivocada dos 
recursos como COFINS, CSLL e CPMF como externos ao orçamento da previdência e passíveis de serem inseridos na rubrica de transferências da União.

Por outro aspecto, Gentil (2006) afirma que a sistemática diversificada de financiamento da seguridade social foi uma importante conquista porque a previdência financiada unicamente pela folha de salários entrou em crise na década de 80 em virtude da recessão na economia brasileira que levou ao desabamento do emprego, concluindo que em momentos de crise apenas a contribuição ao INSS sobre a folha de salários, paga por assalariados e empregadores e por trabalhadores autônomos não seria suficiente para cobrir os gastos com saúde e com os benefícios previdenciários dos filiados ao sistema.

Portanto, deve se frisar que dentre as diversas fontes de custeio previstas no art. 195 da $\mathrm{CF}$ estão às contribuições sociais. Em particular, as contribuições dos empregadores e trabalhadores à seguridade social (contribuição ao INSS), a COFINS inclusive sobre as importações, a CSLL e a receita de concursos de prognósticos e a extinta CPMF cuja receita era distribuída: $21 \%$ para a previdência social; $42,1 \%$ para a saúde; $21,1 \%$ para o Fundo de Combate e Erradicação da Pobreza; e, 15,8\% apropriados pelo orçamento fiscal para aplicação livre de vinculações por meio do mecanismo da DRU. (GENTIL, 2006).

Não obstante, o Estado com o escopo de financiar de forma direta ou indiretamente a economia, o emprego, as exportações e os investimentos acabou se utilizando de forma contundente das renúncias, desonerações tributárias e dos incentivos fiscais.

Um exemplo claro de renúncia foi a MP 795/2017 convertida na Lei n ${ }^{\circ}$ 13.586/2017 que ampliou o regime especial para exploração do petróleo e afins. O texto prevê renúncias envolvendo a apuração do lucro real e a base de cálculo da CSLL, como também um regime especial de importação (art. $5^{\circ}$ ) que dispensa o pagamento de todos os tributos associados (inclusive as parcelas da COFINS e Contribuição para o PIS/PASEP). Segundo a Consultoria da Câmara dos Deputados as renúncias estimadas acumulam a cifra de R\$ 1 trilhão, em 40 anos. Por outro lado, a aprovação desses e dos demais projetos relacionados ignoraram os limites e procedimentos estabelecidos pela $\mathrm{EC} \mathrm{n}^{\circ}$ 95/2016, a Lei de Responsabilidade Fiscal e a Lei de Diretrizes Orçamentárias de 2017. Todas essas normas exigiam conhecimento prévio pelo Parlamento do total de renúncias envolvidas e relatório de impacto identificando as respectivas medidas compensatórias. (ANFIP, 2017).

Por meio da tabela 01, é possível observar os montantes envolvidos nas renúncias tributárias, particularmente, no caso das contribuições sociais: 
Tabela 01 - Renúncias Tributárias em Contribuições Sociais

Valores correntes em R\$ milhões

\begin{tabular}{|c|c|c|c|c|c|c|}
\hline & \multicolumn{2}{|c|}{ Estimativas Bases Efetivas } & \multicolumn{3}{|c|}{ Projeções } \\
\hline & $\mathbf{2 0 1 3}$ & $\mathbf{2 0 1 4}$ & $\mathbf{2 0 1 5}$ & $\mathbf{2 0 1 6}$ & $\mathbf{2 0 1 7}$ & $\mathbf{2 0 1 8}$ \\
\hline $\begin{array}{c}\text { Somas das Renuncias nas contribuições } \\
\text { sociais* }\end{array}$ & 119.452 & 139.566 & 148.948 & 137.884 & 141.177 & 150.415 \\
\hline Soma das renúncias em outras receitas & 103.858 & 116.668 & 121.106 & 125.827 & 129.222 & 137.100 \\
\hline Total das renúncias & 223.310 & 256.234 & 270.054 & 263.711 & 270.399 & 287.515 \\
\hline \% Renuncias Seguridade sobre o Total & 53,5 & 54,5 & 55,2 & 52,3 & 52,2 & 52,3 \\
\hline $\begin{array}{c}\text { \% Renuncias Seguridade sobre o Total de } \\
\text { Contribuições Sociais }\end{array}$ & 18,8 & 20,9 & 22,2 & 20,0 & 18,7 & nd \\
\hline
\end{tabular}

Fonte: ANFIP

*Contribuição para Previdência Social, COFINS, CSLL, Contribuição Social para o PIS-PASEP.

Outro grande e importante aspecto acerca do déficit da previdência está relacionado com a Desvinculação das Receitas da União (DRU). Este instituto denominado Fundo Social de Emergência nasceu por meio da Emenda Constitucional de Revisão $\mathrm{n}^{\circ}$ 01, acrescentando os art. 71, 72, 73 ao Ato das Disposições Constitucionais Transitórias (ADCT). A razão de sua criação era o saneamento financeiro da Fazenda Pública Federal e a estabilização econômica, justificando a sua emergência pela necessidade de um prazo até que fossem aprovadas as medidas capazes de dar ao governo os meios necessários para que o equilíbrio fiscal fosse permanente, prevendo a desvinculação de $20 \%$ (vinte por cento) da arrecadação de todos os impostos e contribuições da União, excetuado o previsto nos incisos I, II e III.

A partir de sua criação a DRU não apenas sofreu diversas prorrogações, como também teve seu percentual de desvinculação majorado. Recentemente, a EC 93/2016 prorrogou a DRU até o dia 31 de dezembro de 2023, ampliando para $30 \%$ (trinta por cento) o percentual das receitas de tributos federais que podem ser usadas livremente e altera quais os tributos podem ser desvinculados, incluindo fundos constitucionais, taxas e compensações financeiras. (SALVADOR, 2017).

Em 1995, Maílson da Nobrega, publicou matéria em defesa a prorrogação do FSE, precursor da DRU, alegando que consiste basicamente em um remanejamento de recursos e que sua prorrogação é devida para que sejam contempladas as reformais cruciais para o Estado e para a preservação do Real sob pena de retornar a inflação caso o FSE não fosse reinstituído. (NOBREGA, 1995). Por outra vertente, Salvador (2010) sustenta que os superávits primários compreendidos entre 2000 e 2007 foram atingidos basicamente pela incidência da DRU nas receitas exclusivas da seguridade social. 
Segundo a Associação Nacional dos Auditores da Receita Federal do Brasil (ANFIP) a desvinculação das receitas da seguridade social ocorre porque na verdade seu orçamento sempre foi superavitário, afirmando que no período compreendido entre 2005 e 2016, o superávit médio anual foi de $\mathrm{R} \$ 50,1$ bilhões, concluindo que a utilização da DRU nunca foi aplicada para solucionar um problema de gestão financeira de recursos, mas alimentar o discurso em prol das reformas tendentes a suprimir direitos da seguridade social (ANFIP, 2017).

As receitas (COFINS, CSLL, PIS/PASEP, outras contribuições e as taxas de órgãos da seguridade) desvinculadas pela DRU, totalizam anualmente os respectivos valores: $\mathrm{R} \$$ 45.860 milhões (2010), R \$ 63.418 milhões (2013), R\$ 63.132 milhões (2014), R \$63.791 milhões (2015), R \$ 99.315 milhões (2016) e R 133.468 milhões. (ANFIP, 2017).

Além da discussão sobre a DRU, os reiterados refinanciamentos e parcelamentos dos débitos tributários também tem sido danosos para as contas públicas e a seguridade social. Por exemplo, em 2016, o governo editou a MP 766/2016, porém, teve sua vigência encerrada devido a sua não apreciação pelo Congresso Nacional. Entretanto, a MP 783/2017 convertida na Lei $n^{\circ}$ 13.496/2017, prevê a redução de juros e multas em ate 99\% (noventa e nove por cento), permitindo o parcelamento do valor principal (sem juros e multas) em até 240 (duzentos e quarenta) meses, atingindo dívidas já renegociadas e reiteradamente não quitadas com potencial de atingir $\mathrm{R} \$ 84$ (oitenta e quatro) bilhões. (ANFIP, 2017).

Para o refinanciamento das dívidas tributárias dos estados e municípios foi criada a MP 778/2017 convertida na Lei 13.485/2017, enquanto a MP 793/2017 foi criada para permitir o parcelamento das dívidas junto à previdência rural, prevendo parcelamentos em até 250 meses e perdão integral de juros e $25 \%$ (vinte e cinco por cento) das multas. Contudo, a referida MP perdeu validade e com isso o Congresso Nacional aprovou a Lei 13.606/2018. Também é importante destacar que os empregadores rurais levaram ao judiciário a questão das contribuições rurais e, finalmente, quando o STF, determinou o pagamento, veio por meio do governo o longo parcelamento e um perdão a boa parte das dívidas. (ANFIP, 2017).

Segundo Achilles Linhares de Campos Frias a dívida ativa da União, em 2017, totalizava R \$ 1,8 trilhão, dos quais mais de R \$ 400 milhões são de dívidas da Previdência. O mesmo ainda critica o fato de deputados devedores votarem textos, concedendo perdão de dívidas, exemplificando pela MP 766/2017 que institui o Programa de Regularização Tributária cujo relator devia cerca de R \$ 67 milhões a União. (SENADO FEDERAL, 2017). 
No mesmo sentido, a ANFIP, em 2017, alertou que os devedores da previdência devem quase três vezes o déficit do setor. Na lista com mais de 500 (quinhentos) nomes aparecem empresas públicas, privadas, fundações, governos estaduais e prefeituras que devem ao Regime Geral da Previdência Social, dentre elas: a Vale (R \$ 275 milhões), JBS (R \$ 1,8 bilhão), a Caixa Econômica Federal (R \$ 549 milhões), o Bradesco (R \$ 465 milhões), o Banco do Brasil (R \$ 208 milhões) e Itaú Unibanco (R \$ 88 milhões). (ANFIP, 2017).

\section{AS (IN)CONSTITUCIONALIDADES DA REFORMA DA PREVIDENCIA PELA PEC 06/2019}

Após as reformas no sistema previdenciário brasileiro, atualmente se debate no Congresso Nacional a PEC 06/2019. Diante disso, o que se objetiva apresentar neste tópico são as flagrantes inconstitucionalidades inseridas em pontos sensíveis estabelecidos no texto da referida emenda.

A priori, é preciso destacar que a possibilidade de reforma constitucional tem como limite as cláusulas pétreas elencadas no rol do $\S 4^{\circ}$ do art. $60 \mathrm{CF}$. Dito isso, é inegável que as propostas atinentes à capitalização, a desconstitucionalização dos principais vetores da previdência e o BPC alteram flagrantemente o núcleo essencial da previdência.

A desconstitucionalização das regras permanentes na $\mathrm{CF} / 88$ já foi tentada no governo FHC, sem sucesso, por meio da PEC n 33/1995, que objetivava a desconstitucionalização das regras dos regimes previdenciários e sua regulamentação total por lei complementar. A PEC 06/2019 promove a desconstitucionalização de regras regentes do RGPS e RPPS, dando nova redação aos art. 40 e 201 da Constituição, mantendo no corpo permanente parâmetros gerais a serem observados pela sua regulamentação por meio de lei complementar.

Consoante a AMB (2019) trata-se de um retrocesso de mais de 30 anos no caso do RGPS e demais de 70 anos no caso dos servidores públicos. Assim, a supressão do corpo permanente da $\mathrm{CF}$ das regras relativas à aquisição de direitos no regime próprio e no regime geral fere o princípio da vedação ao retrocesso social, admitido pela doutrina e pela jurisprudência do STF.

Outro controverso pilar da nova previdência proposto na PEC n 06/2019 é a previsão de que lei complementar organizaria um novo regime de previdência social com base no sistema de capitalização. Embora esta proposta tenha sido afastada momentaneamente pelo Congresso Nacional, alguns comentários devem ser registrados em face da insistência 
governamental em requentar a matéria por meio de outra PEC. Assim, a instituição deste regime individual além de atentar flagrantemente contra a sistemática constitucional da seguridade social e a seus princípios, ofende o princípio da solidariedade regulador da sociedade brasileira e também o princípio da dignidade humana, colocando o direito à previdência social, integrante da seguridade social, em uma ótica individualista e mercantil, contrária à ideia constitucional essencial da solidariedade e coparticipação. Ademais, um documento elaborado pela OIT analisa que a privatização da previdência em países latinoamericanos e no leste europeu se tornou um absoluto fracasso em virtude do acúmulo de evidências sobre os impactos sociais e econômicos ${ }^{5}$, aumentando a desigualdade de renda e gênero, caminhando na contramão do objetivo constitucional de redução das desigualdades e discriminação de todos os tipos (MPF, 2019).

Também deve ser observada a proposta de alteração das regras para a concessão do denominando Benefício de Prestação Continuada - BPC 6 . Conforme o Boletim Estatístico da Previdência Social (BEPS) de novembro de 2018 existem 4,7 milhões de beneficiários do BPC. Dentre estes, 56\% são portadores de deficiência e 44\% são idosos acima de 65 anos. Esse total equivale a pouco mais de $13 \%$ do total de benefícios concedidos pelo Instituto Nacional do Seguro Social (INSS). Em 2018, a despesa com o BPC, somando as duas modalidades, foi de $\mathrm{R} \$ 56,2$ bilhões, o que equivaleu a $4 \%$ das despesas primárias da União ou $0,8 \%$ do PIB. (ANDRADE, COURI, BACCIOTTI, 2019).

Embora o gasto com este benefício assistencial seja ínfimo, proporcionalmente, ao PIB, a PEC 06/2019 ao propor mudanças para a concessão do benefício segue eivada de inconstitucionalidade, pois o art. 203 da CF garante o pagamento de um salário mínimo a titulo de benefício mensal.

Recrudescer a regra para acesso ao BPC além de inconstitucional pela expressa dicção do art. 203 da CF/88 há o enorme risco de retrocesso social e impõe ao necessitado um tratamento desumano, impactando inclusive a sua expectativa de vida. Afinal, Cintra, Lima e Alves (2017), em estudo sobre o impacto do BPC na expectativa de vida saudável dos

\footnotetext{
${ }^{5}$ Disponível em <https://www.diap.org.br/index.php/noticias/agencia-diap/28698-oit-capitalizacao-nao-deucerto-em-nenhum-pais-do-mundo>. Acesso em 20 de agosto de 2019.

${ }^{6} \mathrm{O}$ BPC consiste em um benefício da assistência social previsto no artigo 203 da CF/88 e disciplinado pela Lei $\mathrm{n}^{\circ} 8.742 / 1993$ garante um salário-mínimo mensal à pessoa com deficiência e ao idoso com 65 (sessenta e cinco) anos ou mais que comprovem não possuir meios de prover a própria manutenção nem de tê-la provida por sua família, permitindo que idosos e pessoas com deficiência acessar as condições mínimas de uma vida digna.
} 
idosos brasileiros, concluem que o pagamento do benefício aumenta sensivelmente a expectativa de vida de homens e mulheres idosos no Brasil.

Também, não se deve desconsiderar a diferença da expectativa de vida entre os Estados brasileiros. Enquanto de 2016 para 2017 a expectativa de vida do brasileiro chegou aos 75,8 anos, existe uma enorme discrepância entre os entes da federação, vez que, a maior esperança de vida está em Santa Catarina (79,1 anos), as menores expectativas de vida estão, respectivamente, no Maranhão (70,6 anos) e Piauí (71,1). Apenas a título ilustrativo, considerando as duas regras e as duas menores expectativas de vida no Brasil por meio de um simples cálculo matemático percebe-se a redução sensível de recebimento para o idoso em condição de miserabilidade, demonstrando claramente a desumanidade da proposta.

Tabela 2 - Cálculo BPC x Expectativa de vida

\begin{tabular}{|c|c|c|c|c|c|c|}
\hline Idade & $\begin{array}{c}\text { Regra } \\
\text { Vigente }\end{array}$ & Regra Proposta & 70,6 anos (RV) & 71,1 anos $(\mathrm{RV})$ & 70,6 anos $(\mathrm{RP})$ & 71,1 anos (RP) \\
\hline 60 a 64 & & $\mathrm{R} \$ 400,00$ & & & $\mathrm{R} \$ 24.000,00$ & $\mathrm{R} \$ 24.000,00$ \\
\hline 65 a 69 & $\mathrm{R} \$ 998,00$ & $\mathrm{R} \$ 400,00$ & $\mathrm{R} \$ 59.880,00$ & $\mathrm{R} \$ 59.880,00$ & $\mathrm{R} \$ 24.000,00$ & $\mathrm{R} \$ 24.000,00$ \\
\hline 70 ou mais & $\mathrm{R} \$ 998,00$ & $\mathrm{R} \$ 998,00$ & $\mathrm{R} \$ 5.988,00$ & $\mathrm{R} \$ 24.950,00$ & $\mathrm{R} \$ 5.988,00$ & $\mathrm{R} \$ 24.950,00$ \\
\hline Total & & & $\mathrm{R} \$ 65.868,00$ & $\mathrm{R} \$ 84.830,00$ & $\mathrm{R} \$ 53.988,00$ & $\mathrm{R} \$ 72.950,00$ \\
\hline
\end{tabular}

O descalabro da nova previdência não se dá apenas nas claríssimas inconstitucionalidades e ilegalidades, contribuindo para o desmonte de um sistema de seguridade social pautado nos objetivos fundamentais da República brasileira. O discurso fiscal, de ajustes para garantir aposentadorias se esvai como a areia entre os dedos em razão das desigualdades e retrocessos sociais que a reforma irá implementar.

Percebe-se isso, claramente, no tratamento desigual entre classes. Basta lembrar que o governo dizia que todos dariam a sua parcela de contribuição. Na verdade, o resultado é outro, nitidamente, perceptível pelo PL 1.645/2019 que pretende reestruturar as forças armadas.

Em primeiro lugar, a economia total líquida de $\mathrm{R} \$ 10,45$ bilhões com a reestruturação da carreira militar é uma ofensa ao sacrifício exigido dos civis, vez que, a reestruturação ocasionará um impacto negativo de $\mathrm{R}$ \$ 86,85 bilhões. As regras de transição dos militares para os civis são mais brandas. A inclusão dos adicionais de disponibilidade militar e o adicional de habilitação ocasionará aumentos consideráveis nas remunerações dos militares. A 
desigualdade de tratamento é tão gritante que sargentos, cabos e soldados têm criticado a proposta por beneficiar as altas patentes em detrimento deles. (DEFESANET, 2019).

Derradeiramente, não se deve olvidar que o Brasil assumiu perante a comunidade internacional o papel de corresponsável na promoção dos direitos humanos, participando ativamente na promulgação da Declaração Americana dos Direitos e Deveres do Homem e da Declaração Universal dos Direitos Humanos, bem como aderiu a Agenda 2030 para o Desenvolvimento Sustentável cujo objetivo ODS 10 prescreve a busca pela redução das desigualdades, com a redução dentro dos países e entre eles. Inclusive, por expressa dicção constitucional o país deve reger as suas relações internacionais pela prevalência dos direitos humanos. Portanto, não há como promover uma reforma previdenciária que desnature o escopo constituinte estabelecido na $\mathrm{CF} / 88$, muito menos impor reformulação constitucional que venha a ferir os objetivos pátrios, os direitos humanos e sociais e os princípios constitucionais sob pena de evidente retrocesso social e de promover um revisionismo político inapropriado de conquistas consagradas na Constituição.

\section{CONSIDERAÇÕES FINAIS}

O debate sobre a reforma da previdência fundamentado pela crise financeiro-fiscal do Estado, o fraco desempenho da economia e a sua relação com o aumento do desemprego e do trabalho informal vem desde a promulgação da constituição de 1988 e foi motivador para a realização de seis emendas constitucionais a fim de reformar o sistema constitucional da seguridade social.

Percebe-se que no centro deste debate duas grandes vertentes se confrontam. Uma que considera a proteção social como tarefa do Estado e se coaduna com o sistema protetivo consagrado no texto constitucional e outra de recorte liberal, priorizando um sistema de previdenciário de responsabilidade individual do cidadão, claramente, representado pela proposta de se alterar a sistemática constitucional de repartição para um o regime de capitalização individual proposto no corpo da EC 06/2019.

Estas duas vertentes antagônicas se confrontam desde a promulgação da Constituição de 1998. Inclusive, o debate sobre o déficit previdenciário paira exatamente nas diferentes visões sobre o sistema de seguridade social brasileiro.

Todavia, não se pode olvidar que a vontade do legislador pátrio na Constituição de 1988 expressa o resultado de conquistas após lutas emancipatórias, traduzido em políticas 
públicas com o fito de superar desigualdades históricas no país. Esta vertente social do constitucionalismo brasileiro se plasma por meio de uma ideia de construir uma sociedade livre, justa e solidária que se propõe a erradicar a pobreza e a marginalização, assim como a redução das desigualdades e a produção do bem de todos, sem preconceitos de origem de raça, cor, sexo, idade e quaisquer outras formas de discriminação.

Este conjunto de objetivos fundamentais sem sombra de dúvida se cristaliza na dicção do art. 195 da CF/88 ao mencionar a estrutura solidária para o financiamento da seguridade social, pois transmite de maneira explicita a visão de uma sociedade organizada para a proteção de pessoas em condição de vulnerabilidade durante a vida. Reforça ainda esta análise o cuidado do legislador em limitar as emendas constitucionais pelas chamadas cláusulas pétreas com o escopo de salvaguardar valores fundamentais para a sociedade para que não fiquem expostos a variação de vontade de uma maioria, ainda que qualificada.

Diante do evidente retrocesso social que se desenha no desejo draconiano e egoísta em produzir tamanho descalabro de ordem constitucional urge que seja respeitado o espírito das conquistas angariadas no processo constituinte e que a vontade manifesta de subjugar comandos pétreos constitucionais sem a devida transparência, o devido debate e participação dos atores sociais não ponham em xeque nossos objetivos fundamentais e levem uma horda de brasileiros aos dissabores da indiferença e do ocaso social.

\section{REFERÊNCIAS}

ANDRADE, Alexandre; COURI, Alexandre; BACCIOTTI, Rafael. Impactos fiscais da PEC $\mathrm{n}^{\circ}$ 06/2019: o caso do benefício de prestação continuada. Nota Técnica ${ }^{\circ}{ }^{\circ} 28$ de 28 de fevereiro de 2019. Disponível em

<https://www2.senado.leg.br/bdsf/bitstream/handle/id/554601/NT28_Reforma_Previdencia_ Novo_BPC.pdf>. Acesso em 23 de agosto de 2019.

ANFIP. Análise da Seguridade Social em 2017. Brasília: ANFIP, 2017. Disponível em <https://www.anfip.org.br/wp-content/uploads/2018/12/Livros_28_11_2018_14_51_18.pdf>. Acesso em 29 de julho de 2019.

ANFIP. Devedores da Previdência devem quase três vezes o déficit do setor, 2017.

Disponível em <https://www4.anfip.org.br/noticia.php?id_noticia=21375>. Acesso em $22 \mathrm{de}$ agosto de 2019.

AMORIM, Wanderson Lima de. A seguridade social de 2006 a 2016: Uma análise sobre a sustentabilidade do sistema. Monografia. Especialização lato sensu em orçamento público. Brasília: Instituto Legislativo Brasileiro, 2017. 70p. Disponível em 
<https://www2.senado.leg.br/bdsf/bitstream/handle/id/542666/TCC_Wanderson_Lima_de_A morim.pdf?sequence=1>. Acesso em 01 de agosto de 2019.

ASSOCIAÇÃO DOS MAGISTRADOS DO BRASIL - AMB. Reforma da Previdência sob a visão da AMB, 2017. Disponível em

<https://www.amb.com.br/previdencia/uploads/cartilha.pdf>. Acesso em 31 de março de 2017.

CAMBRAIA, Túlio. Estudo Técnico n 10/2019. In: Consultoria de orçamentos e fiscalização financeira. Orçamento da Seguridade Social. Brasília, 2019. Disponível em

$<$ https://www2.camara.leg.br/orcamento-da-uniao/estudos/2019/et-10-2019-orcamento-daseguridade-social>. Acesso em 30 de julho de 2019

CINTRA, Renato Souza; LIMA, Everton Emanuel Campos de; ALVES, Luciana Correia. O impacto do benefício de prestação continuada na expectativa de vida saudável dos idosos brasileiros em 2008. Dissertação (Mestrado em Demografia). Instituto de Filosofia e Ciências Humanas. Universidade Estadual de Campinas, 2008. 105p.

FAGNANI, Eduardo. O déficit da previdência e a posição dos juristas. In: Textos para discussão. Instituto de Economia. UNICAMP: São Paulo, 2017. p.1-28. Disponível em <www.eco.unicamp.br/docprod/downarq.php?id=3534\&tp=a>.

Acesso em 31 de julho de 2019.

FATTORELLI, Maria Lucia. A máscara do déficit da previdência. In: Auditoria Cidadã, 2017<https://auditoriacidada.org.br/conteudo/mascara-do-deficit-da-previdencia/>.

Disponível em <https://auditoriacidada.org.br/conteudo/mascara-do-deficit-da-previdencia/>. Acesso em 02 de agosto de 2019.

FATORELLI, Maria Lucia. O déficit da Previdência é fake. Disponível em <https://www.anfip.org.br/artigo-clipping-e-imprensa/o-deficit-da-previdencia-e-fake/>. Acesso em 22 de agosto de 2019

GENTIL, Denise Lobato. A política fiscal e a falsa crise de seguridade social brasileira Análise financeira do período 1990-2005. Tese (Doutorado em Economia). Instituto de Economia. Universidade Federal do Rio de Janeiro, 2006. 358p.

INSTITUTO BRASILEIRO DE DIREITO PREVIDENCIÁRIO - IBSP. Nota Técnica IBDP $\mathrm{n}^{\circ}$ 01/2019 sobre a MP 871/2019. Disponível em <https://www.ibdp.org.br/?p=976>. Acesso em 23 de agosto de 2019

IBRAHIM, Fábio Zambitte. Curso de Direito Previdenciário. Niterói: Impetus, 2012.

DELGADO, Guilherme; JACCOUD, Luciana; NOGUEIRA, Roberto Passos. Seguridade Social: redefinindo o alcance da cidadania. In: Políticas sociais: acompanhamento e análise. Boletim de Políticas Sociais, Brasília, v.1, n.17, 2009. Disponível em <http://www.ipea.gov.br/portal/images/stories/PDFs/politicas_sociais/bps_17_vol001_comple to.pdf> . Acesso em 20 de agosto de 2019. 
KERTZMAN, Ivan. Curso prático de Direito Previdenciário. Salvador: JUSPODIVM, 2013.

MARTINS, Sergio Pinto. Direito da Seguridade Social. São Paulo: Atlas, 2004.

MINISTÉRIO PÚBLICO FEDERAL - MPF. Procuradoria Federal dos Direitos do Cidadão. Nota Técnica ${ }^{\circ}$ 10/2019-PDFC de 05 de junho de 2019. Disponível em $<$ http://pfdc.pgr.mpf.mp.br/mwginternal/de5fs23hu73ds/progress?id=UpQ815RLlyT9JbJcWxdlPVExox0VOwPpTDNU6glBy J4> .Acesso em 01 de agosto de 2019

NÓBREGA, Maílson da. Em defesa do Fundo Social de Emergência. In: Folha de São Paulo de 15 de setembro de 1995. Disponível em <https://www1.folha.uol.com.br/fsp/1995/9/15/dinheiro/5.html>. Acesso em 19 de agosto de 2019.

ONU. Declaração Universal dos Direitos Humanos, 1948. Disponível em $<$ https://nacoesunidas.org/wp-content/uploads/2018/10/DUDH.pdf>. Acesso em 20 de agosto de 2019.

SALVADOR, Evilásio. Fundo Público e Seguridade Social no Brasil. São Paulo: Cortez, 2010.

SALVADOR, Evilasio da Silva. O desmonte do financiamento da seguridade social em contexto de ajuste fiscal. Serv. Soc. Soc., São Paulo, n. 130, p. 426-

446, Dezembro. 2017. Disponível em

$<$ http://www.scielo.br/scielo.php?script=sci_arttext\&pid=S0101-

$66282017000300426 \& \operatorname{lng}=\mathrm{en} \& \mathrm{nrm}=\mathrm{iso}>$. Acesso em 09 de agosto de

2019. http://dx.doi.org/10.1590/0101-6628.117.

SENADO FEDERAL. O fracasso da revisão constitucional de 1994, 2008. Disponível em <https://www12.senado.leg.br/noticias/materias/2008/08/19/o-fracasso-da-revisaoconstitucional-de-1994>. Acesso em 20 de agosto de 2019.

SENADO FEDERAL. Comissão Parlamentar de Inquérito do Senado Federal destinada a investigar a contabilidade da previdência social, esclarecendo com precisão as receitas e despesas do sistema, bem como todos os desvios de recursos (CPIPREV). Relatório Final. Disponível em <https://legis.senado.leg.br/comissoes/mnas?codcol=2093\&tp=4>. Acesso em 23 de agosto de 2019

SENADO FEDERAL. Dívidas não cobradas e desonerações geram déficit da Previdência, dizem auditores. 2017. Disponível em

$<$ https://www12.senado.leg.br/noticias/materias/2017/05/03/cpi-da-previdencia-dividas-naocobradas-e-desoneracoes-sao-causa-de-deficit-dizem-auditores $>$. Acesso em 22 de agosto de 2019 